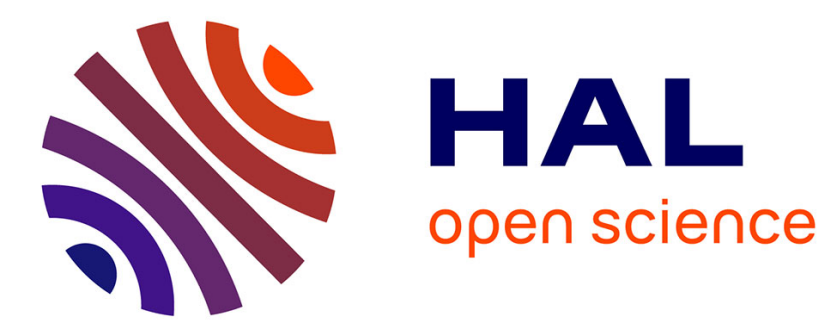

\title{
Anthropocentric Workplaces of the Future Approached through a New Holistic Vision
}

\author{
Andrea Bettoni, Marco Cinus, Marzio Sorlini, Gókan May, Marco Taisch, \\ Paolo Pedrazzoli
}

\section{- To cite this version:}

Andrea Bettoni, Marco Cinus, Marzio Sorlini, Gókan May, Marco Taisch, et al.. Anthropocentric Workplaces of the Future Approached through a New Holistic Vision. IFIP International Conference on Advances in Production Management Systems (APMS), Sep 2014, Ajaccio, France. pp.398-405, 10.1007/978-3-662-44736-9_49. hal-01387906

\section{HAL Id: hal-01387906 \\ https://hal.inria.fr/hal-01387906}

Submitted on 26 Oct 2016

HAL is a multi-disciplinary open access archive for the deposit and dissemination of scientific research documents, whether they are published or not. The documents may come from teaching and research institutions in France or abroad, or from public or private research centers.
L'archive ouverte pluridisciplinaire HAL, est destinée au dépôt et à la diffusion de documents scientifiques de niveau recherche, publiés ou non, émanant des établissements d'enseignement et de recherche français ou étrangers, des laboratoires publics ou privés. 


\title{
Anthropocentric Workplaces of the Future Approached Through a New Holistic Vision
}

\author{
Andrea Bettoni ${ }^{1}$, Marco Cinus ${ }^{1}$, Marzio Sorlini ${ }^{1}$, Gökan May ${ }^{2}$, Marco Taisch ${ }^{2}$, \\ and Paolo Pedrazzoli ${ }^{1}$ \\ ${ }^{1}$ University of Applied Sciences and Arts of Southern Switzerland, ISTePS, Galleria \\ 2 Via Cantonale 2c, CH-6928 Manno, Switzerland \\ \{andrea.bettoni, marco.cinus, marzio.sorlini, paolo.pedrazzoli\}@supsi.ch \\ 2 Politecnico di Milano, Piazza Leonardo da Vinci 32, I-20131 Milano, Italy \\ \{gokan.may, marco.taisch\}@polimi.it
}

\begin{abstract}
The human dimension is growing in importance in the cultural and scientific debate surrounding the arising of workplace and factory of the future visions. Having people at the centre of the factory is already recognized as a main enabler for making the most out of their skills and capacities while at the same time achieving an environment that can both motivate employed workers and attract new skilled ones. The present paper proposes a novel concept aimed at defining new socially sustainable workplaces that adapt to workers' anthropometric dimensions within worker-aware production systems that are designed and operated to capitalize on workers' skills and experience while at the same time promoting their development. Moreover it envisions the integration of the factory in the social and environmental context by promoting the creation and provision of worker-centric services that turn the factory from a society-affecting entity into an integration-promotion body.
\end{abstract}

Keywords: socially sustainable workplaces, anthropocentric workplace, context-aware factory

\section{Introduction}

Companies today are declaring in their Corporate Social Responsibility (CSR) reports that they consider as primary the attention towards all the company stakeholders' and especially employees' behaviour, where the workers are referred as the company's greatest asset. However, few organizations actually treat their employees this way. In his book [28], Walker discusses on the methodologies and approaches that an organization can implement in order to put the employee at the centre of the working environment, postulating that "only when management recognizes that the firm exists to provide an ethical environment in which employees can fully develop and apply their business skills, will the firm be positioned for true success". Royer et al. [21] points out that in a strategic perspective the employees' voice is an important business component where organizations can rely on for pursuing success. Recognizing the worker as a critical 
resource for the enterprise success, as detailed in [18], has been the starting point for the development of structured employee-centred Human Resource Management (HRM) strategies. This vision produced the notion of employees as human capital: they collectively represent the sum of all their knowledge, skills, and abilities, as well as additional characteristics such as energy, drive and motivation they bring with them to the factory [3]. "Knowing" the worker is thus fundamental in order to be able to foresee the value generation capabilities of the company.

According to Sinha et al. [22], the "organizations of tomorrow will be employeecentric". The positive correlation between organizations' performances and employee recognition as a critical resource in strategic management has been demonstrated by case studies and investigations on real production environments' performances $[16,26]$.

But, what does it mean putting the employee "at the centre" of the organization? Which are the tools supporting this shift? Which are the levers and the knowledge areas employee-centric organizations may rely on to pursue their objective?

Guided by the above mentioned research questions, this study aims at defining the new anthropocentric workplaces of the future. In this sense, Chapter 2 investigates the interaction between employee and working context, and Chapter 3 highlights the main cornerstones of these anthropocentric workplaces. Finally, Chapter 4 tries to summarize the key developments of the next years.

\section{Employee and the Working Context Interaction}

Achieving the transition to an industry where the human dimension is a key cornerstone requires, in the first place, to know each single person involved in the production processes. A reliable, holistic and accessible characterization of workers is thus called for. According to surveys of the European Commission [6, 17] quality of work and employment has four complementary dimensions: ensuring career and employment security, maintaining and promoting the health and wellbeing of workers, developing skills and competences, and reconciling working and non-working life. Accordingly four elements through which the employee working environment / context interaction are here identified and examined: (1) Ergonomics and Anthropometry, (2) Functional Capacities, (3) Knowledge and (4) Personal needs and private life - work balance.

\subsection{Ergonomics and Anthropometry}

Ergonomics encompasses the relationship between humans, machine systems, job design and the work environment. Various studies $[5,8,10-12,15]$ argue that the goal of ergonomics is to enable workers to be more effective by matching the requirements and demands of the job to the abilities and limitations of the workers rather than trying to force the workers to fit the job. 
The social impacts of ergonomics are obvious and empirical studies reported in [20] have proven that ergonomics in the workplace has also an impact on effectiveness and profitability, making this discipline important even from a pure economic point of view. The most obvious cause of the increasing interest in this field is the rising costs related with injuries on the workplace. In order to foster the adoption of ergonomics in manufacturing strategies it is also important to raise the perception that proper prevention measures can have positive impact on productivity and quality. The introduction of advanced technologies and automation in production has not yet been accompanied by parallel advances in ergonomics, resulting into workers' pathology that are not necessarily major accidents, but injuries deriving from repeated micro-traumas at muscoloskeletal and nervous system level $[5,19]$.

\subsection{Functional Capacities}

Modern ergonomics evaluation practices also consider functional capacities of the workers. In order to put a strong emphasis on the relationship between the workers' abilities and the assigned task, the analysis of ergonomics and functional capacities are kept separated.

Tasks assignment strategies and methodologies can be traced back to 1911 in Taylor's "Scientific Management" [25]. Taylor's principles for manual workers productivity emphasized efficient and effective object motion to ensure the best possible outcome. The object, its necessary and sufficient motion in space and time, and the manual worker's movements are integrated to achieve control over the manufacturing variables and meet the requirements for a quality product.

Approaches deriving from traditional scientific management theories require a careful and in-depth analysis of the operations and working tasks, on one side, and of worker physical capacities and characteristics on the other. In fact, physical characteristics of the worker have a meaningful impact on its performances [24].

The analysis of the matching between the worker functional characteristics and capabilities and the assigned tasks is elicited in a proper workplace design. This simultaneous consideration of worker/workplace and worker/job binomials is often at the basis of Total Quality Management [7], or Business Process Reengineering methodologies, with the goal to improve working conditions and promote a sustainable working life where work environment improvement efforts are a resource for both the workplace and the individual.

\subsection{Knowledge}

As stated by Waitley [27] "Today, the source of power has shifted from capital resources to human resources, from natural resources to knowledge resources, from position status to relationship process, and from shareowner power to customer power". Knowledge is one of the most important resource employees bring to the company, and those who want to succeed have the challenge to identify, create, share, store, and internally disseminate the employee's knowledge [14]. 
Adopting Knowledge Management tools in industrial contexts has become a necessity, and organizations need to manage these intellectual assets effectively. This is true for both big competitors and for SMEs.

Investing in KM systems is a way to facilitate the experience and knowledge flow between the employees of a firm [13]. Bhattacharya et al. [1] shows that knowledge and skills are strongly related with company performances. Proper Knowledge Management Systems have been thus adopted in various industrial contexts in order to both collect and reuse workers knowledge for the benefit of the company, using direct and indirect techniques [23].

\subsection{Personal Needs}

Finally, workers' behaviour and personal needs are rarely gathered and included in workers' profiles. These data are usually collected using traditional (e.g. questionnaire-based) means and included in ad-hoc "workers-care" initiatives or campaigns. Many social studies can be mentioned reporting results of these investigations and several tools and methodologies [2] are adopted especially in big companies in order to ensure workers personal wishes collection and re-use for organizational improvement.

Nowadays, many companies are trying to respond to the worker requirements enhancing the working conditions on one hand, and a sustainable work participation on the other hand. Some of these initiatives are suggested by CSR implementation strategies, where the employee is one of the (most important) stakeholders the company has to take care of. The characteristics related to the production processes, such as scheduled time, machine productivity, etc. may impose a constraint when addressing the worker personal requirements during the setting phase of the working conditions. These conditions, in fact, include schedule and workplace flexibility, autonomy and accountability, teamwork, management by objectives, strict deadlines, etc. that are all elements constrained both to processes and workers characteristics [9].

\section{Anthropocentric Workplaces of the Future}

This chapter provides a novel concept that aims at defining new socially sustainable workplaces where the human dimension is a key cornerstone. Workers are foreseen at the centre of the factory, on the one hand, in terms of workplace adaptation and production planning, to skills, expertise and characteristics of each single worker and, on the other hand, in terms of capability to make the most out of workers' knowledge and potentials across all age groups and different roles, simultaneously fostering enhanced workers safety. Moreover, this concept promotes the vision of an effective integration of this anthropocentric factory within the social environment toward the implementation of context-aware factories that encourage and take advantage of extended services to the workers in terms of accessibility, inclusiveness, work-life balance and work satisfaction. 
The main human-centric factors governing production taken into considerations are: (1) Efficiency, (2) Occupational Health and Safety with related Risk Management and (3) Effective use of workers knowledge. In this sense, evolving characteristics of each single worker in terms of age, expertise, attitudes and health conditions, imply an ever changing profile of skills and tasks, that needs to be taken into consideration in terms of work organization and workplace adaptation and in terms of capability to make the most out of workers' knowledge and potentials.

The Anthropocentric Workplace of the Future concept will lays its foundation on four cornerstone, which are:

1. KNOW the worker / factory / context

2. Design \& Deploy the workplace

3. Plan the Production and Organize the Work

4. Produce with context-aware factories integrated in their social environment

In the following subsections, a brief description of these cornerstones are provided.

\subsection{KNOW}

Know the Worker. Knowing the worker means to track in real time the evolving profile of the worker, through his characterization in the following four dimensions: (1) Anthropometry, a detailed picture of the worker with the most significant dimensions of the human body, (2) Functional Capacities intended as the sensorial, physical and cognitive capacities considering also age and gender related issues, (3) Knowledge resident in each worker which could be of any benefit for the factory or colleagues, (4) Personal needs of the worker, paying particular attention to aspects more related to the personal and private life of the worker such as territorial origin, nationality, family composition, physical activity, mobility, religion, leisure, etc. [4].

The collection of all these elements will be combined in order to create a worker profile, which is complete and changing over time.

Know the Factory. Unlike the traditional characterization of a factory which is based on production capacity, productivity, lead times and other economic and financial driven KPIs, the proposed concept aims at characterizing the factory from a worker point of view. This is done to identify and track potential interactions between workers and the elements of the working environment interacting with them. The main factory elements represented will include production KPIs, jobs/task with required skills, working shifts, organizational structure, processes, workplaces shapes and placing, intra-worker interactions and corporate services. These elements will form the basis to create a formalized representation of the factory also complemented with all the key risk factors, essential to assess the adequacy of workers' evolving conditions to the assigned jobs.

The combination of these elements will allow to create a reliable, evolving worker-centric view of the factory. 
Know the Context. The environmental and social context in which factories are placed will be analyzed through stakeholder-specific relationship management approaches, deployed on the three dimensions of sustainability (economic, social and environmental). This will allow to create a comprehensive awareness and understanding of the territory and trends in which the factory is located, providing valuable inputs to a dynamic decision making process, promoting contextaware strategies and objectives.

\subsection{Design \& Deploy the Workplace}

Data and information gathered thanks to the KNOW cornerstone represent a comprehensive, consistent and evolving knowledge base enabling the design of worker-centric, factory-conscious and context-aware workplaces. This will result into designs of effective workplaces based on: (1) worker characteristics, (2) factory requirements and (3) context/environment needs and constraints. Concrete outputs will be thus the designs of anthropocentric model workplaces addressing the needs of the specific target group "plant and machine operator" working in manufacturing production environments.

\subsection{Plan the Production and Organize the Work}

The KNOW knowledge base and the worker-centric workplaces designs deriving from the previous two cornerstones are taken as structured inputs for the worker- and context- aware organization and planning of production-related jobs, tasks and human resources. Methodologies and tools of this third cornerstone are enabling the valuable and dynamic integration of workers, workplaces and production requirements taking into account constraints and opportunities deriving from the factory and the contexts. The solutions and approaches allow the identification and characterization of the better performing allocation of resources to changing and evolving jobs and tasks, also including comprehensive plans for human resources management and effective training of the workforce.

\subsection{Produce with context-aware factories integrated in their social environment}

The last cornerstone is meant to favour and ease the integration of the workers into the social and environmental context where the factory is placed. The collected personal needs of the workers, and constraints/requirements and opportunities of the social context where the factory is placed, are both matter of this cornerstone in order to (1) minimize the environmental impact of the factory activities (identifying sustainability-enhancing strategies), (2) transforming the factory from a society-affecting entity into an integration-promotion body proactively favouring workers valuable inclusion into the social environment. 


\section{Conclusion}

The paper presented a novel concept that places the worker at the centre of the factory by defining the next generation of socially sustainable workplaces. An analysis of the key elements for achieving these workplaces has been carried out identifying the main areas of development and the related gaps and needed improvements.

The four cornerstones at the basis of the proposed concept, also currently investigated within the European FP7 project Man-Made, have been then presented. Starting from the formalization of the knowledge concerning the worker, the factory seen from a worker's perspective and the context where the factory operates, methods and tools for anthropocentric design of the workplace and of the factory operation management at large have been identified. Finally, means for a valuable integration of the factory in the social environment through the provision of personalized services aimed at improving the balance between working and non-working life are discussed.

The piece of research described in this paper represents the starting building block for the development of specific methodologies and tools aimed at supporting the implementation of the discussed vision in real production environments. This will promote a leap towards the next level of human-factory-context balance for the factory of the future.

\section{Acknowledgement}

This work has been partly funded by the European Commission through ManMade (MANufacturing through ergonoMic and safe Anthropocentric aDaptive workplacEs for context aware factories in EUROPE) project (Grant Agreement No: FoF.NMP.2013-3 6090730). The authors wish to acknowledge the Commission for its support. The authors also wish to acknowledge their gratitude and appreciation to all the Man-Made partners for their contribution during the development of various ideas and concepts presented in this work.

\section{References}

1. Bhattacharya, M., Gibson, D.E., Doty, D.H.: The effects of flexibility in employee skills, employee behaviors, and human resource practices on firm performance. Journal of Management 31(4), 622-640 (2005)

2. Burchell, M., Robin, J.: The Great Workplace: How to Build It, How to Keep It, and Why It Matters. Wiley (2010)

3. Cardy, R.L., Miller, J.S., Ellis, A.D.: Employee equity: Toward a person-based approach to hrm. Human Resource Management Review 17(2), 140-151 (2007)

4. Corti, D.: Human resource management. In: Errasti, A. (ed.) Global Production Networks: Operations Design and Management. Taylor \& Francis (2013)

5. Eby, R., Mahone, D.: How to use ergonomics as a loss control tool. Risk Management 38(3), 42-7 (1991) 
6. European Commission: Europe 2020: a strategy for smart, sustainable and inclusive growth. Brussels: European Commission (2010)

7. Evans, J., Lindsay, W.: The Management and Control of Quality. Thomson/SouthWestern (2005)

8. Fernberg, P.: Tayloring the workstation to the worker. Modern Office Technology 37(6), 26-30 (1992)

9. Frenkel, A., Bendit, E., Kaplan, S.: The linkage between the lifestyle of knowledgeworkers and their intra-metropolitan residential choice: A clustering approach based on self-organizing maps. Computers, Environment and Urban Systems 39, 151-161 (2013)

10. Griffin, G.: Understanding ergonomics. Rural Relecomunciations 11(5), 58-61 (1992)

11. Hoffer, W.: Errors on the job can be reduced. Nation's Business 76(4), 62 (1988)

12. Knill, B.: Human factors engineering: An ongoing quest at at\&t. Material Handling Engineering 44(2), 37-8 (1989)

13. Lee, L.T.S., Sukoco, B.M.: The effects of entrepreneurial orientation and knowledge management capability on organizational effectiveness in taiwan: The moderating role of social capital. International Journal of Management 24(3) (2007)

14. Liker, J., Meier, D.: Toyota Talent: Developing Your People the Toyota Way. McGraw Hill professional, McGraw-Hill Education (2007)

15. Lindo, D.: It's time to emphasize ergonomics. Supervision 52(5), 14-16 (1991)

16. Nayar, V.: Employees First, Customers Second: Turning Conventional Management Upside Down. Harvard Business Review Press (2013)

17. Parent-Thirion, A., Vermeylen, G., Van Houten, G., Lyly-Yrjänäinen, M., Biletta, I., Cabrita, J., Niedhammer, I.: Fifth european working conditions survey. Luxembourg: Eurofound, Publications Office of the European Union. (2012)

18. Pfeffer, J.: Producing sustainable competitive advantage through the effective management of people. The Academy of Management Executive 9(1), 55-69 (1995)

19. Rickert, K.: Ergonomics in the office. RISK MANAGEMENT-NEW YORK- 39, 18-18 (1992)

20. Rowan, M.P., Wright, P.C.: Ergonomics is good for business. Work Study 43(8), 7-12 (1994)

21. Royer, S., Waterhouse, J.M., Brown, K.A., Festing, M.: Employee voice and strategic competitive advantage in international modern public corporations : an economic perspective. European Management Journal 26(4), 234-246 (August 2008)

22. Sinha, N., Kakkar, N.K., Gupta, V.: Uncovering the secrets of the twenty-firstcentury organization. Global Business and Organizational Excellence 31(2), 49-56 (2012), http://dx.doi.org/10.1002/joe.21414

23. Small, C.T., Sage, A.P.: Knowledge management and knowledge sharing: A review. Information, Knowledge, Systems Management 5(3), 153-169 (2006)

24. Smith, E.A.: The role of tacit and explicit knowledge in the workplace. Journal of knowledge Management 5(4), 311-321 (2001)

25. Taylor, F.W.: The principles of scientific management. Harper (1914)

26. Ulrich, D., Ulrich, W., Goldsmith, M.: The Why of Work: How Great Leaders Build Abundant Organizations That Win. McGraw-Hill Education (2010)

27. Waitley, D.: Empires of the Mind: Lessons to Lead and Succeed in a KnowledgeBased World. Positive paperbacks, Nicholas Brealey Publishing Limited (1996)

28. Walker, J.: Ethics and the Employee-Centric Firm. Itasca Books (2011) 